\title{
Ni-P Coated Sn Powders as Anode for Lithium Secondary Batteries
}

\author{
Yong Nam $\mathrm{Jo}^{\dagger}$, Dongmin $\mathrm{Im}^{\dagger \dagger}$, Jae Jung Kim, and Seung M. Oh* \\ School of Chemical and Biological Engineering, and Research Center for Energy Conversion \& Storage \\ Seoul National University, Seoul 151-744, Korea \\ ${ }^{\dagger}$ Korea Electron Technology Institute. \#68, Yatap-dong, Bundang-gu, Seongnam-si, Gyeonggi-do, 463-816, Korea \\ ${ }^{\dagger \dagger}$ Materials Lab, Samsung Advanced Institute of Technology PO BOX 111, Suwon, 440-600, Korea
}

(Received February 15, $2007:$ Accepted March 5, 2007)

\begin{abstract}
Nano-sized Sn particles were coated with Ni-P layer using an electroless deposition method and their anodic performance was tested for lithium secondary batteries. Uniform coating layers were obtained, of which the thickness was controlled by varying the $\mathrm{Ni}^{2+}$ concentration in the plating bath. It was found that the $\mathrm{Ni}-\mathrm{P}$ layer plays two important roles in improving the anodic performance of $\mathrm{Sn}$ powder electrode. First, it prevents the inter-particle aggregation between Sn particles during the charge/discharge process. Second, it provides an electrical conduction pathway to the Sn particles, which allows an electrode fabrication without an addition of conductive carbon. A pseudooptimized sample showed a good cyclability and high capacity $\left(>400 \mathrm{mAh} \mathrm{g}^{-1}\right)$ even without conductive carbon loading.
\end{abstract}

Keywords : Li secondary batteries, Anode, Tin nanoparticles, Nickel-phosphorus, Electroless deposition.

\section{Introduction}

Metallic Sn has been projected as one of the promising alternatives to carbon-based anode for lithium secondary batteries. The theoretical specific capacity of $\mathrm{Sn}\left(992 \mathrm{mAh} \mathrm{g}^{-1}\right)$ is much higher than that of graphite $\left(372 \mathrm{mAh} \mathrm{g}^{-1}\right) .^{1-4)}$ Its practical use is, however, still hindered due to an unsatisfactory cycle life that is largely caused by a severe volume expansion/contraction during the alloying and de-alloying reaction with $\mathrm{Li}^{+}$ions. Such a large volume change is known to induce a pulverization of Sn metal particles, which would eventually deactivate their $\mathrm{Li}^{+}$storage ability ${ }^{5-8)}$ Nano-sized Sn particles can be an approach to avoid the pulverization since the absolute volume change would be minimized. While some improvement has been achieved with this nano-sized Sn approach, ${ }^{9-11)}$ another problem has emerged. Repeated alloying and de-alloying reaction leads to an aggregation of nano-sized Sn particles into larger ones, which would be pulverized again upon cycling. ${ }^{12,13)}$

One strategy to improve the cycle life of nano-sized Sn particles may be the coating with conductive materials. It is intuitive that the coated layer can act as a barrier to suppress the interparticle aggregation by decreasing the chance for direct contact between Sn particles. It is also very likely that the conductive coating layer can provide an electrical contact to the Sn core. In this work, we have ascertained this concept using the Ni-P coated Sn particles that were synthesized by an electroless deposition technique. ${ }^{14.15)}$ The preparation and electrochemical performance of Ni-P coated nano-sized Sn powders (NCSP) are reported. Also, the roles of Ni-P coating in improving the cyclability are discussed.

*E-mail: seungoh@plaza.snu.ac.kr

\section{Experimental}

$\mathrm{Ni}-\mathrm{P}$ layer was coated on the surface of nano-sized Sn powder (Alfa Aesar) by an electroless deposition technique employing sodium hypophosphite as the reducing agent. The composition of plating baths is listed in Table $1 .{ }^{15)}$ The thickness of Ni-P layer was controlled by the concentration of $\mathrm{NiSO}_{4} \cdot 6 \mathrm{H}_{2} \mathrm{O}$ with the other variables being fixed (Table 1). The $\mathrm{pH}$ of plating solution was adjusted to 9.0 by the addition of a dilute $\mathrm{NaOH}$ solution. In practice, the $\mathrm{Sn}$ powder $(0.2 \mathrm{~g})$ was dispersed in the plating solution $(100 \mathrm{~mL})$ by sonication for $20 \mathrm{~min}$, and then stirred for $3 \mathrm{~h}$ at $80^{\circ} \mathrm{C}$. The $\mathrm{Ni}-\mathrm{P}$ coated $\mathrm{Sn}$ powder thus obtained was collected by filteration, and rinsed with ethanol and distilled water.

The elemental analysis was made by inductively-coupled plasma emission spectroscopy (ICP) using a Shimadzu ICPS7500 spectrophotometer. The $\mathrm{x}$-ray diffraction analysis was conducted with a Model Bruker D8 Advance x-ray diffractometer (XRD) using $\mathrm{CuK}_{\mathrm{a}}$ radiation. The powder morphology was examined using a JEOL JSM-6700F field-emission scanning electron microscope (FE-SEM). The thickness and uniformity of Ni-P layer on the surface of $\mathrm{Sn}$ was examined with a JEOL JEM-2000 EXIl transmission electron microscope (TEM).

Table 1. The composition of plating baths for electroless Ni-P deposition on Sn nanoparticles

\begin{tabular}{cc}
\hline Component & Concentration $/ \mathrm{mol} \mathrm{dm}^{-3}$ \\
\hline Glycolic acid & 0.20 \\
Sodium citrate & 0.10 \\
Sodium hypophosphite & 0.20 \\
Nickel sulfate & Ni-1: $0.02, \mathrm{Ni}-2: 0.03, \mathrm{Ni}-3: 0.04$ \\
\hline
\end{tabular}


For the preparation of composite Sn electrodes, a mixture of active material (bare Sn powder or NCSP), Super-P (as a carbon additive for conductivity enhancement), and poly(vinylidene fluoride) (PVdF, as a binder) (72:14:14 by weight unless otherwise specified) was dispersed in $\mathrm{N}$ methyl pyrrolidone (NMP), and mixed for $2 \mathrm{~h}$ in a mortar and pestle. The resulting slurry was spread on a piece of copper foil (as a current collector, $25 \mathrm{~mm}$ thickness and cut into $1 \mathrm{~cm}^{2}$ apparent area) using a doctor blade. The electrode was vacuum-dried at $120^{\circ} \mathrm{C}$ for $12 \mathrm{~h}$, and subsequently rollpressed in order to enhance the inter-particle contact and to ensure a better adhesion to the current collector.

Beaker-type three electrode cells were used for the galvanostatic charge-discharge measurements. All the cell assembly was carried out in an Ar-filled glove box. Lithium foil (Cyprus Co.) was used as the counter and reference electrode, a porous polypropylene membrane as the separator, and $1.0 \mathrm{M} \mathrm{LiClO}_{4}$ solution in ethylene carbonate (EC) and diethyl carbonate (DEC) $(1: 1$ by volume) as the electrolyte. Cells were galvanostatically cycled between 0.0 and $2.0 \mathrm{~V}$ (vs. $\mathrm{Li} / \mathrm{Li}^{+}$) at a current density of $50 \mathrm{~mA} \mathrm{~g}$. The galvanostatic intermittent titration technique (GITT) was used to monitor the evolution of internal resistance during cycling, where a current pulse of $50 \mathrm{~mA} \mathrm{~g}^{-1}$ was applied for $10 \mathrm{~min}$ to measure the closed-circuit voltage $(\mathrm{CCV})$ and turned off for $20 \mathrm{~min}$ to obtain the quasi-open-circuit voltage (QOCV). The sequential current pulse was applied for both charging and discharging period in the range of $0.0-2.0 \mathrm{~V}$. The internal resistance was calculated from the difference between the $\mathrm{CCV}$ and QOCV in each voltage transient. GITT experiments were carried out with a WBCS-3000 battery cycler (Xeno Co.) while all the other electrochemical measurements with a TOSCAT-3000U battery cycler (Toyo System Co.) at ambient temperature.

\section{Results and Discussion}

Three samples were prepared according to the conditions listed in Table 1. The average weight ratio of phosphorus to nickel in the coating layer determined by ICP was about 0.1 , suggesting that less-crystalline (or amorphous) Ni-P phase has been formed. ${ }^{14)}$ The Ni contents in NCSP samples are plotted in Fig. 1. The Ni-P deposition increases with an increase in the $\mathrm{Ni}^{2+}$ concentration in the plating bath. Especially, it increases considerably when $\mathrm{Ni}^{2+}$ concentration changes from 0.03 to $0.04 \mathrm{~mol} \mathrm{dm}^{-3}$ while there appears a slight increase from 0.02 to $0.03 \mathrm{~mol} \mathrm{dm}^{-3}$. The electroless deposition of Ni-P employing sodium hypophosphite is known to be an autocatalytic reaction that is accelerated once a certain amount of nickel is deposited. Therefore, the reaction would proceed slowly if the nucleation rate is not fast enough. It has to be noted that the $\mathrm{Ni}^{2+}$ concentration in this work is substantially low compared to the typical electroless $\mathrm{Ni}-\mathrm{P}$ deposition procedure. ${ }^{15)}$ The nucleation rate below 0.03 $\mathrm{mol} \mathrm{dm}^{-3}$ appears too slow to facilitate the deposition process, indicative of the existence of a critical point between 0.03 and $0.04 \mathrm{~mol} \mathrm{dm}^{-3}$ where the nucleation of Ni-P phase

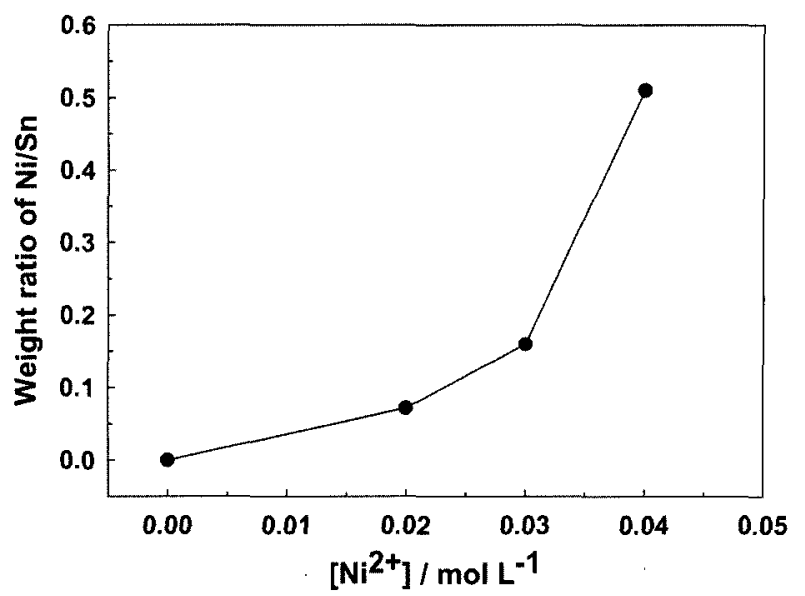

Fig. 1. Weight ratio of Ni/Sn in the Ni-P coated nano-sized Sn particle (NCSP) samples as a function of $\mathrm{Ni}^{2+}$ concentration in the plating baths.

becomes significant.

The morphologies of bare Sn and NCSP samples prepared at different $\mathrm{Ni}^{2+}$ concentrations are compared in Fig. 2. The particle size of bare $\mathrm{Sn}$ is about $50-300 \mathrm{~nm}$. The morphology of $\mathrm{Ni}-1$ and $\mathrm{Ni}-2$ powders is similar to that of bare $\mathrm{Sn}$, but a slight increase in particle size and roughened surface indicate the Ni-P deposition (Figs. $2 b$ and 2c). The morphology of Ni-3 appears somewhat different, where the average particle size has been slightly increased and several tens nano-sized grains of Ni-P layer can be clearly recognized on the surface of Sn particles (Fig. 2d).

Figs. $3 \mathrm{a}$ and $3 \mathrm{~b}$ show the transmission electron microscopy (TEM) images of bare $\mathrm{Sn}$ and Ni-3 sample, respectively. The Ni-P coating layer is clearly seen outside of Sn particles in Fig. 3b. The layer appears very uniform with thickness of over $20 \mathrm{~nm}$.

Fig. 4 shows the $\mathrm{x}$-ray diffraction (XRD) patterns of bare Sn and NCSP samples. SnO phase is identified on the bare Sn sample, indicating that its surface is partially oxidized. On the other hand, $\mathrm{SnO}_{2}$ phase is commonly found in the NCSP samples, probably due to an oxidation at the elevated temperature $\left(80^{\circ} \mathrm{C}\right)$ and the basic condition $(\mathrm{pH}=9)$ of plating bath. ${ }^{16,17)}$ The characteristic broad peak corresponding to amorphous $\mathrm{Ni}-\mathrm{P}$ can be noticed around $45^{\circ}$, which is overlapped with the peaks corresponding to $\mathrm{Sn}$ and $\mathrm{Ni}_{3} \mathrm{Sn}_{4}$ phases to make its identification difficult. The intensity of this broad peak around $45^{\circ}$ increases with an increase in $\mathrm{Ni}^{2+}$ concentration in the plating bath, indicative of a thicker deposition of Ni-P layer, which is in a good agreement with the ICP results shown in Fig. 1. Some intermetallic phases of $\mathrm{Ni}-\mathrm{Sn}$ are also found. Yoon et al. ${ }^{18)}$ reported that $\mathrm{Ni}_{3} \mathrm{Sn}_{4}$ and $\mathrm{Ni}_{3} \mathrm{P}$ phases form at the interface between $\mathrm{Sn}$ and $\mathrm{Ni}-\mathrm{P}$ layer in their study of Ni-P deposition on $\mathrm{Sn}-\mathrm{Ag}$ alloy. Even though $\mathrm{Ni}_{3} \mathrm{P}$ phase is not found in our NCSP samples, $\mathrm{Ni}_{3} \mathrm{Sn}_{4}$ and a metastable phase that is not described in the equilibrium phase diagram can be identified in the XRD data. ${ }^{19,20)}$ With the accumulation of $\mathrm{Ni}-\mathrm{P}$ layer, the intensity of peaks corresponding to $\mathrm{Ni}_{3} \mathrm{Sn}_{4}$ and the metastable phase increases whereas those corresponding to metallic Sn 

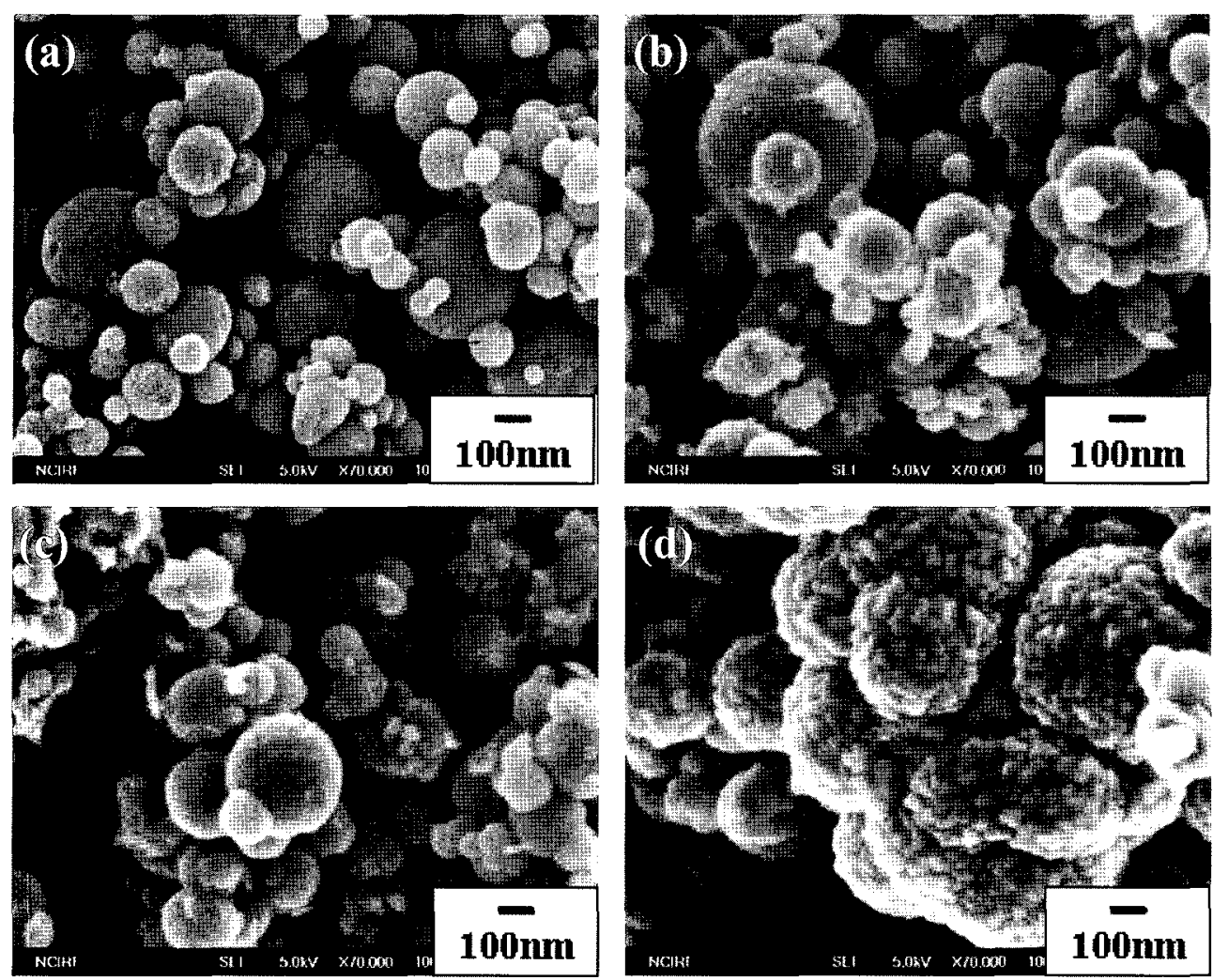

Fig. 2. The FE-SEM images of (a); bare $\mathrm{Sn},(\mathrm{b}) ; \mathrm{Ni}-1,(\mathrm{c}) ; \mathrm{Ni}-2$, and (d); Ni-3 particles. Note the change in size and morphology of particles as a function of $\mathrm{Ni}^{2+}$ concentration in the plating bath.
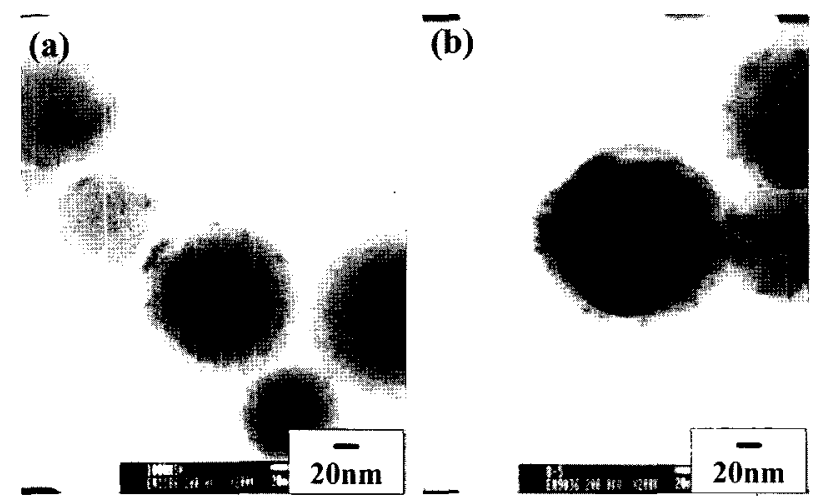

Fig. 3. The TEM images of (a); bare Sn and (b); Ni-3 particles. Note that the Ni-P layer (the lighter image) is coated on the surface of $\mathrm{Sn}$ particles (the darker image) in (b).

decrease, which is possibly due to a reduced $\mathrm{x}$-ray beam intensity penetrating the Ni-P layer and finally reaching the Sn core. It is thus inferred that at least two phases including $\mathrm{Ni}_{3} \mathrm{Sn}_{4}$ and a metastable phase exist between the $\mathrm{Sn}$ core and amorphous Ni-P coating layer.

Fig. 5a shows the galvanostatic voltage profiles of bare $\mathrm{Sn}$ recorded in the first two cycles of charge and discharge. Fig. $5 \mathrm{~b}$ shows the differential capacity plot of a bare Sn electrode in the first cycle and Fig. 5c shows the differential capacity plots during the first charge for the samples listed in Table 1. The plateau in Fig. 5a or the peak in Fig. 5b appearing around $1.4 \mathrm{~V}$ vs. $\mathrm{Li} / \mathrm{Li}^{+}$in the first charging period is ascribed to the decomposition of electrolyte on Sn surfaces. ${ }^{21.22)}$

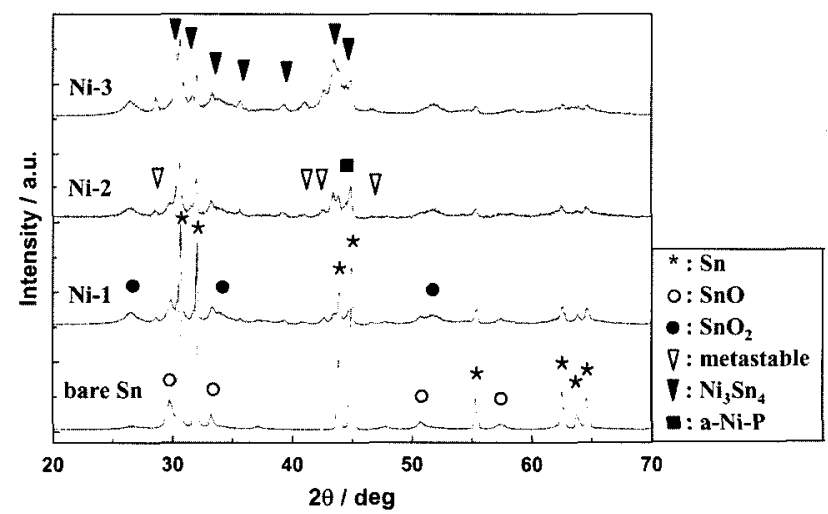

Fig. 4. The XRD patterns of bare Sn and NCSP samples. Note the evolution of new phases in the electroless plating process.

As show in Fig. 5c, this peak can be located in the bare Sn and $\mathrm{Ni}-1$ electrodes, but not in the Ni-2 and Ni-3 electrodes. Obviously, the coating thickness or uniformity in Ni-1 particles is not enough to cover the Sn surface completely while both Ni-2 and Ni-3 particles are covered so effectively that the exposure of metallic Sn surface to the electrolyte is negligible. The peaks near $1.1 \mathrm{~V}$ vs. $\mathrm{Li}^{2} \mathrm{Li}^{+}$representing the reduction of $\mathrm{SnO}$ to metallic $\mathrm{Sn}$ are recognized in all the samples. (Fig. 5c). ${ }^{12)}$ The intensity of this peak is the largest in the profile of bare Sn anode, but gradually diminished as the Ni-P layer becomes thicker. Possibly, an add-up of Ni-P layer has reduced the weight fraction of $\mathrm{SnO}$ and part of $\mathrm{SnO}$ has been converted to $\mathrm{SnO}_{2}$ in the plating process as 

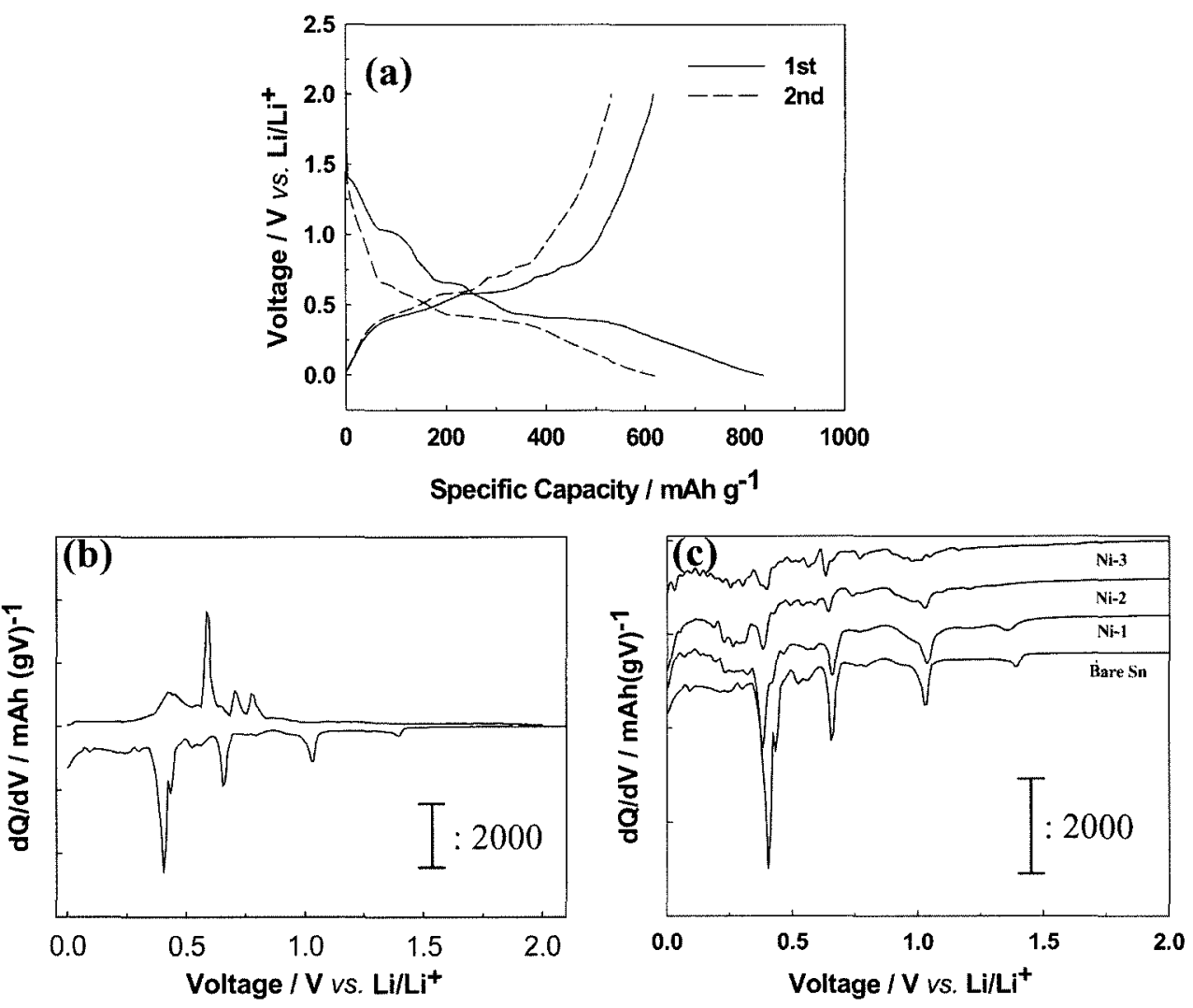

Fig. 5. (a); The galvanostatic charge/discharge voltage profiles of bare Sn electrode in the first two cycles, (b); the differential capacity plot of bare Sn electrode in the first cycle, and (c); the differential capacity plots of bare Sn and NCSP electrodes in the first charge. Note in (c) the variation of peak intensity at 1.1 and $1.4 \mathrm{~V}$ regions that are relevant to the irreversible reactions, and the peaks at $<0.7 \mathrm{~V}$ that are associated with the alloying/de-alloying reactions of $\mathrm{Li}-\mathrm{Sn}$ phase.

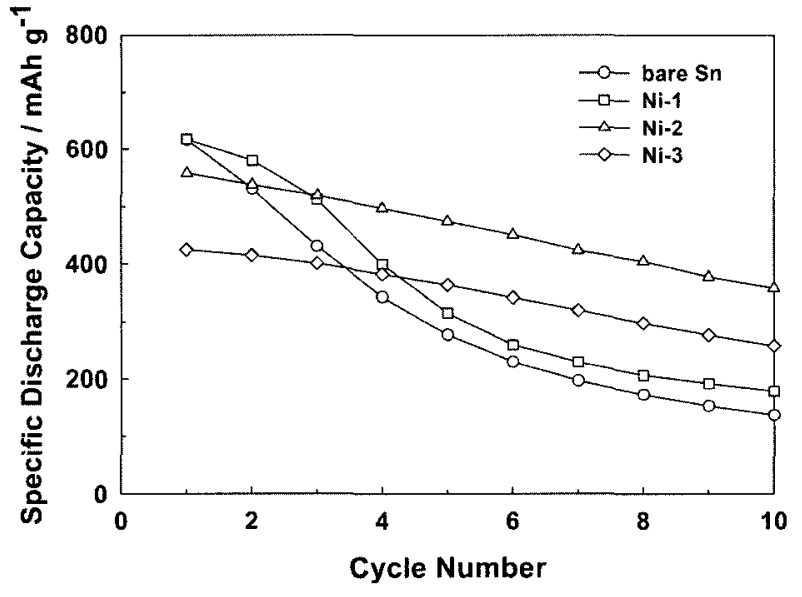

Fig. 6. The specific discharge capacity of bare Sn and NCSP electrode upon cycling. Note that the NCSP electrodes exhibit a better cyclability at the expense of discharge capacity.

indicated in the XRD results (Fig. 4). The peaks below $0.7 \mathrm{~V}$ are assigned to the alloying and de-alloying reactions of $\mathrm{Li}$ Sn phase.

The variation of specific discharge capacity of bare $\mathrm{Sn}$ and NCSP electrodes is shown in Fig. 6. It is clearly seen that the cycle life is improved by the Ni-P coating, which is counter-balanced by a steady decrease in the discharge capacity that is caused by the inactiveness of amorphous Ni$\mathrm{P}$ phase for alloying reaction with $\mathrm{Li}^{+}$ions.

Fig. 7 shows the SEM images of bare Sn and Ni-2 electrodes taken before and after cycling. The $\mathrm{Sn}$ particles in fresh bare $\mathrm{Sn}$ electrode are uniformly distributed over the whole electrode as shown in Fig. 7a. On the other hand, the original morphology of Sn particles is hardly recognized in the cycled electrode (Fig. 7b). The size becomes as large as a few microns and the particles are unevenly distributed after 10 cycles, indicative of a severe aggregation of bare Sn particles during the alloying and de-alloying reaction with $\mathrm{Li}^{+}$ ions. Ni-2 electrode shows a different behavior as shown in Figs. $7 \mathrm{c}$ and $7 \mathrm{~d}$. Except for a slight enlargement in particle size, the shape of particles appears unchanged even after 20 cycles. Therefore, it can be concluded that the Ni-P layer coated on Sn particles effectively plays as a barrier to discourage the particle aggregation, which can account for the better cycle performance observed in the NCSP electrodes. The cyclability of Ni-1 sample is, however, only slightly better than that of bare Sn sample (Fig. 6), suggesting that the amount of coated Ni-P phase in this sample is not enough to prevent the particle aggregation.

In addition to the barrier role, the Ni-P layer that carries a high electronic conductivity is likely effective to maintain the electronic conduction path to and from the Sn particles while they are repeatedly expanded and contracted. In order to ver- 

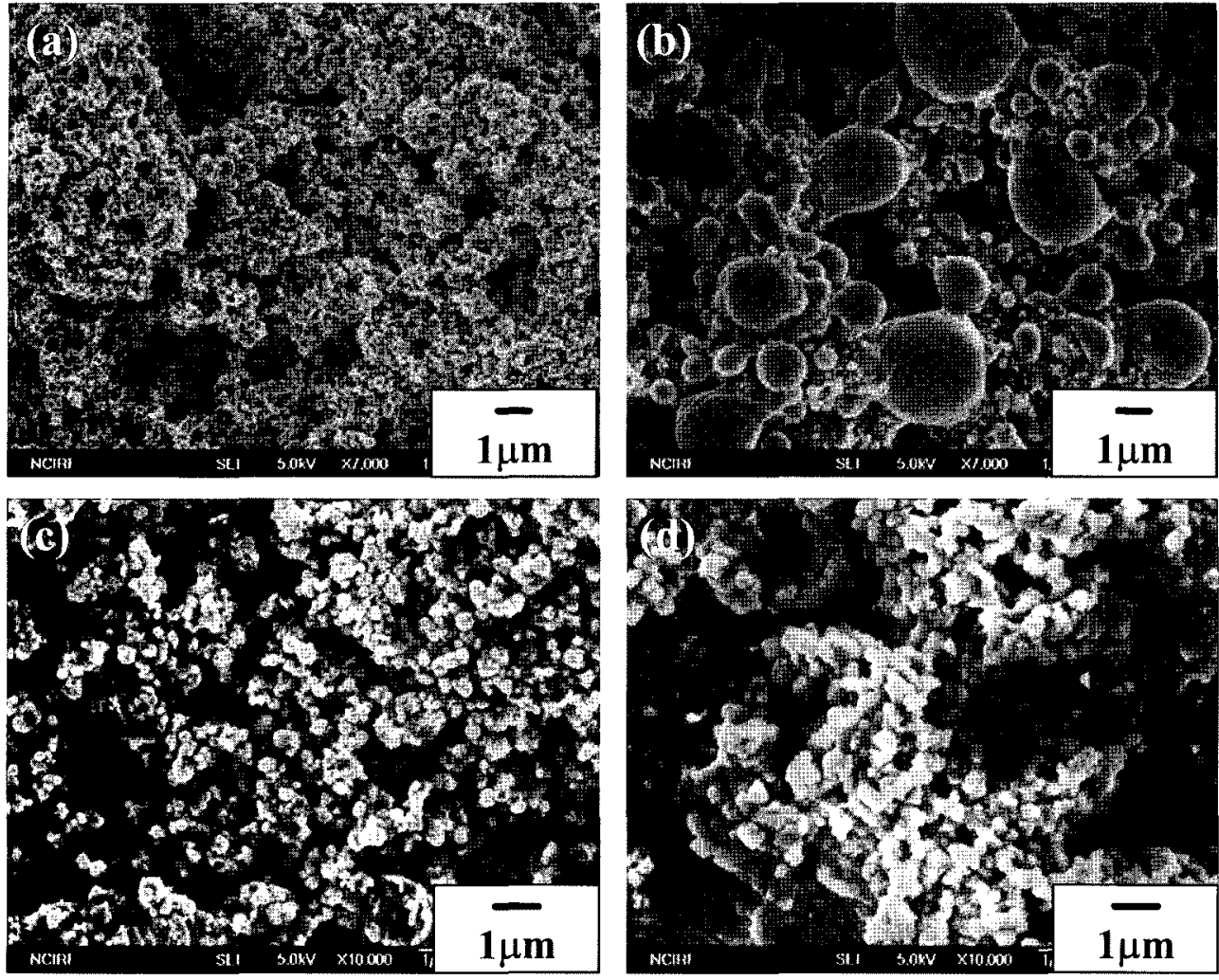

Fig. 7. The FE-SEM images of bare Sn and Ni-2 electrodes: (a); bare Sn electrode before cycling, (b); bare Sn electrode after 10 cycles, (c); Ni-2 electrode before cycling, and (d); $\mathrm{Ni}-2$ electrode after 20 cycles.
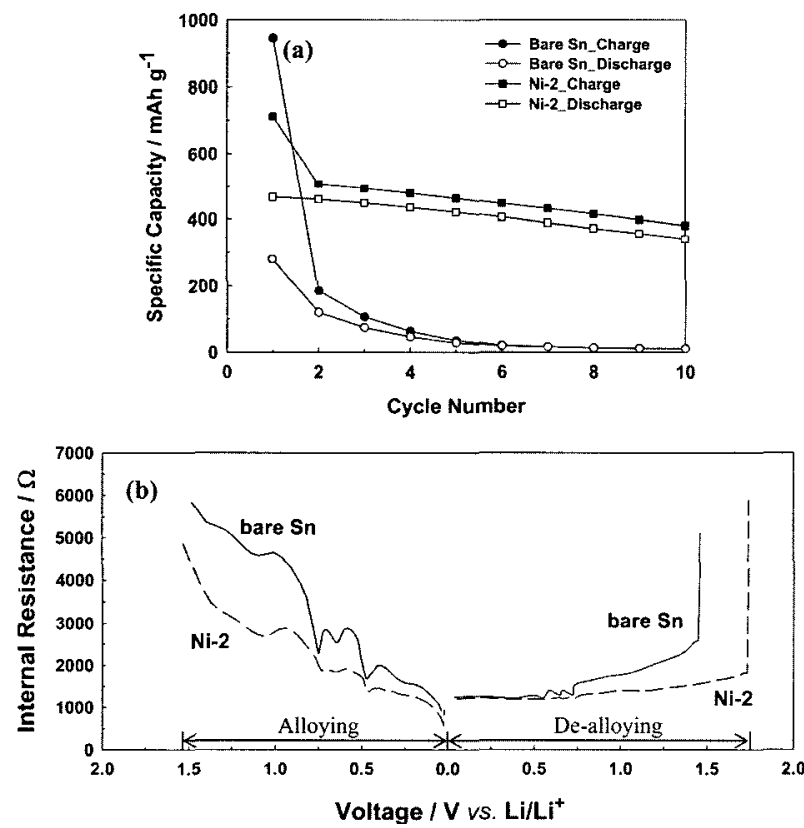

Fig. 8. (a); The cycle life performance of bare $\mathrm{Sn}$ and $\mathrm{Ni}-2$ electrodes that were fabricated without the conductive carbon, and (b); the evolution of internal resistance in the first cycle that was traced by the GITT experiment.

ify this hypothesis, the electrodes were prepared without the conductive carbon and electrochemically characterized. Fig. 8 a shows the variation of specific capacity with cycling for the bare $\mathrm{Sn}$ and $\mathrm{Ni}-2$ electrode. The bare $\mathrm{Sn}$ electrode rap- idly loses its $\mathrm{Li}^{+}$storage ability after first discharge while the $\mathrm{Ni}-2$ electrode exhibits a much better cyclability. The GITT has been employed to validate the effectiveness of $\mathrm{Ni}-\mathrm{P}$ coating in enhancing the electronic conduction by measuring the internal resistance of anodes. The evolution of internal resistances for bare $\mathrm{Sn}$ and $\mathrm{Ni}-2$ electrodes that were fabricated without the conductive carbon is shown in Fig. 8b. The internal resistance decreases during the charging (alloying) period while it increases during the discharging (de-alloying) period. The decrease of internal resistance in the charging period can be explained by a better contact between particles that is provided by a volume expansion of $\mathrm{Sn}$ particles as a result of alloying reaction with $\mathrm{Li}^{+}$ions and electrons. The increase of internal resistance in the discharging period is, however, caused by a breakdown of the conductive network that is in turn caused by a volume contraction of $\mathrm{Sn}$ particles in the de-alloying process. Note that the electrode layer is not so elastic that once-expanded layer upon charging remains swollen even after a discharging. Similar phenomena have been reported in the case of $\mathrm{Li}-\mathrm{Si}$ alloy. ${ }^{23)}$ In this work, the internal resistance of $\mathrm{Ni}-2$ is much lower than that of bare $\mathrm{Sn}$ in both the charge and discharge period. It is now clearer that the Ni-P layer plays an additional role in providing an electronic path to and from the Sn particles.

\section{Conclusion}

Electroless Ni-P deposition has been performed on the surface of $\mathrm{Sn}$ particles. The amorphous Ni-P phase is found on 
the surface of $\mathrm{Sn}$ particles, and intermetallic phases such as $\mathrm{Ni}_{3} \mathrm{Sn}_{4}$ and a metastable phase are found at the interface between $\mathrm{Sn}$ and Ni-P layer. The Ni-P layer thickness was controlled in the range of tens of nanometers by varying the concentration of nickel sulfate in the plating bath. It has been shown that the Ni-P coating layer on the nano-sized Sn particles reduces the decomposition of electrolyte on the metallic Sn and allows a better cycle life since this layer suppresses the aggregation of $\mathrm{Sn}$ particles and keeping the electronic path to and from the Sn particles. On the other hand, the Ni-P coating gives an unfavorable effect on the specific capacity due to its inactiveness for the reaction with $\mathrm{Li}^{+}$ions. The Ni-P layer thickness should thus be optimized by trading-off between the capacity and cyclability.

\section{Acknowledgements}

This work was supported by KOSEF through Research Center for Energy Conversion and Storage, and by the Division of Advanced Batteries in NGE Program.

\section{References}

1. Y. Idota, T. Kubota, A. Matsufuji, Y. Maekawa, T. Miyasaka, TinBased Amorphous Oxide: High Capacity Lithium-Ion-Storage Material, Science, 276, 1395 (1997).

2. M. Winter, J. O. Besenhard, M. E. Spahr, P. Novak, Insertion Electrode Materials for Rechargeable Batteries, Adv. Mater., 10, 725 (1998).

3. J. Wang, I. D. Raistrick, R. A. Huggins, Behavior of Some Binary Lithium Alloys as Negative Electrodes in Organic Solvent-Based Electrolytes, J. Electrochem. Soc., 133, 457 (1986).

4. G. R. Goward, F. Leroux, W. P. Power, G. Ouvrard, W. Dmowski, T. Egami, L. F. Nazar, On the Nature of Li Insertion in Tin Composite Oxide Glasses, Electrochem. Solid-State Lett., 2, 367 (1999).

5. L. Y. Beaulieu, K. W. Eberman, R. L. Turner, L. J. Krause, J. R. Dahn, Colossal Reversible Volume Changes in Lithium Alloys, Electrochem. Solid-State Lett., 4, A137 (2001).

6. Z. Peng, Z. Shi, M. Liu, Mesoporous $\mathrm{Sn}_{-} \mathrm{TiO}_{2}$ Composite Electrodes for Lithium Batteries, Chem. Commun., 21, 2125 (2000).

7. L. Fransson, E. Nordström, K. Edström, L. Haggström, J. T. Vaughey, M. M. Thackeray, Structural Transformations in Lithiated'$\mathrm{Cu}_{6} \mathrm{Sn}_{5}$ Electrodes Probed by In Situ Mo"ssbauer Spectroscopy and X-Ray Diffraction, J. Electrochem. Soc., 149, A736 (2002).

8. B. Veeraraghvan, A. Durairajan, B. Haran, B. Popov, R. Guidotti, Study of Sn-Coated Graphite as Anode Material for Secondary Lithium-Ion Batteries, J. Electrochem. Soc., 149, A675 (2002).
9. H. Li, Q. Wang, L. Shi, L. Chen, X. Huang, Nanosized SnSb Alloy Pinning on Hard Non-Graphitic Carbon Spherules as Anode Materials for a Li Ion Battery, Chem. Mater., 14, 103 (2002).

10. P. Limthongkul, H. Wang, E. Jud, Y. Chiang, Metal Oxide Composites for Lithium-Ion Battery Anodes Synthesized by the Partial Reduction Process, J. Electrochem. Soc., 149, A1237 (2002).

11. N. Li, C. R. Martin, A High-Rate, High-Capacity, Nanostructured Sn-Based Anode Prepared Using Sol-Gel Template Synthesis, J. Electrochem. Soc., 148, A164 (2001).

12. I. A. Courtney, W. R. McKinnon, J. R. Dahn, On the Aggregation of Tin in SnO Composite Glasses Caused by the Reversible Reaction with Lithium, J. Electrochem. Soc., 146, 59 (1999).

13. H. Li, L. Shi, W. Lu, X. Huang, L. Chen, Studies on Capacity Loss and Capacity Fading of Nanosized SnSb Alloy Anode for Li-Ion Batteries, J. Electrochem. Soc., 148, A9I5 (2001).

14. W. Riedel, Electroless Nickel Plating, Finishing Publication, 9, Stevenage (1991).

15. I. Koiwa, M. Usuda, K. Yamada, T. Osaka, Effect of Heat-Treatment on Properties of Electroless-Deposited Nickel-MolybdenumPhosphorus Alloy Films, J. Electrochem. Soc., 135, 718 (1988).

16. P. E. Alvarez, S. B. Ribotta, M. E. Folquer, C. A. Gervasi, J. R. Vilche, Potentiodynamic Behaviour of Tin in Different Buffer Solutions, Corros. Sci., 44, 49 (2002).

17. S. A. M. Refaey, F. Taha, T. H. A. Hasanin, Electrochemical behavior of $\mathrm{Sn}-\mathrm{Ni}$ nanostructured compound in alkaline media and the effect of halide ions, Appl. Surf. Sci., 227, 416 (2004).

18. J. -W. Yoon, S. -B. Jung, Growth kinetics of $\mathrm{Ni}_{3} \mathrm{Sn}_{4}$ and $\mathrm{Ni}_{3} \mathrm{P}$ layer between $\mathrm{Sn}-3.5 \mathrm{Ag}$ solder and electroless $\mathrm{Ni}-\mathrm{P}$ substrate, J. Alloys Comp., 376, 105 (2004).

19. T. Watanabe, K. Arai, T. Hirose, M. Chikazawa, Relationship between Crystallographic Structure of Electroplated Ni-Sn Alloy Film and Its Thermal Equilibrium Diagram, J. Jpn. Inst. Met., 63, 489 (1999).

20. H. Mukaibo, T. Sumi, T. Yokoshima, T. Momma, T. Osaka, Electrodeposited Sn-Ni Alloy Film as a High Capacity Anode Material for Lithium-Ion Secondary Batteries, Electrochem. SolidState Lett., 6, A218 (2003).

21. L. Y. Beaulieu, S. D. Beattie, T. D. Hatchard, J. R. Dahn, The Electrochemical Reaction of Lithium with Tin Studied By In Situ AFM, J. Electrochem. Soc., 150, A419 (2003).

22. S. D. Beattie, T. Hatchard, A. Bonakdarpour, K. C. Hewitt, J. R. Dahn, Anomalous, High-Voltage Irreversible Capacity in Tin Electrodes for Lithium Batteries J. Electrochem. Soc., 150, A710 (2003).

23. J. H. Ryu, J. W. Kim, Y.-E. Sung, S. M. Oh, Failure Modes of Silicon Powder Negative Electrode in Lithium Secondary Batteries, Electrochem. Solid-State Lett., 7, A306 (2004). 